\title{
Lament for the humanities in continuing medical education
}

E very year, following my tussle with the Royal College website, I wonder when the axe will fall. Will I be disbarred first or deranged?

Over four decades, continuing medical education (CME) has grown to an imperative. We cannot maintain credentials without "keeping up." We understand why. Medicine changes constantly and rapidly, embracing innovation, rejecting obsolescence. Events that "count" as good learning must be peer-reviewed and unbiased.

During the same period, humanities in medical education has mushroomed. Medical schools foster humanistic learning and accreditors approve courses. Similarly, interdisciplinarity is encouraged and rewarded.

As a historian and a clinician, I want to keep up in both. My research is history - research that, I believe, is relevant to clinical practice. Not only does it illustrate how current standards came into existence, its pursuit is a mirror of clinical practice. History is predicated on the idea that things change. It proclaims the importance of life-long learning; its method - question, evidence and interpretation - reflects diagnostic reasoning.

Here's the rub. Medical history conferences struggle to obtain CME accreditation.

CME accreditation is complex and expensive. To meet requirements, hopeful planners must provide multipaged applications, draft programs, learning objectives, bias-free budgets, disclosures, evaluation instruments and detailed lists of people. Many CME offices must generate cost-recovery income. Therefore applicants pay fees that they can try to pass on to delegates.

Medical history meetings attract historians, librarians, archivists, students, nurses, and other professionals. Practising physicians comprise the smallest group. I attend peer-reviewed meetings of the Canadian Society for the History of Medicine and the American Association for the History of

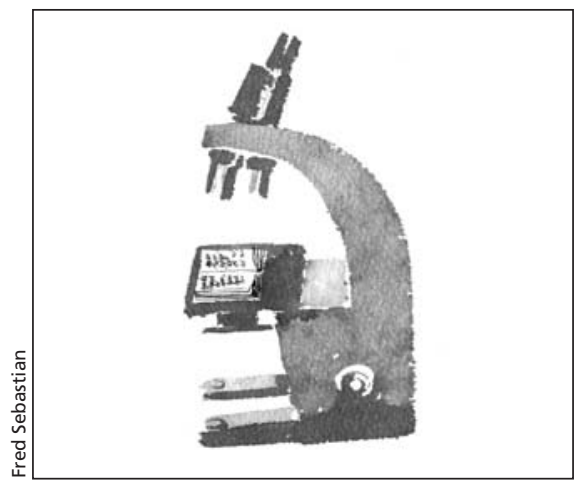

Medicine (AAHM), which often meet in centres without medical schools.

Each year, a willing volunteer has to beg harried organizers to cooperate with CME stipulations. For nonmedical planners, it is baffling, annoying, and intrusive - although they are amazingly patient. Having convinced planners to deliver the information, we must then find an accreditor.

Accreditation demands that conferences justify their clinical relevance. Here history runs smack against a deeply rooted suspicion about its utility. (If the humanities are irrelevant to practitioners, why are they increasing in education?) Those "inside-the-box" learning outcomes that we select at professional websites cannot encompass the myriad ways in which history alters perceptions of ourselves, patients, treatments and diseases. Sometimes our applications are rejected because the CME offices - situated in schools boasting robust humanities programs - decide that history is not clinically relevant. (The notable exception is the Queen's University Office of Continuing Professional Development, which has accredited medical-history meetings whenever and wherever their jurisdiction will allow.)

If the accreditation hurdle is overcome, there's the issue of the fee. For example, a medical school offered to accredit a recent AAHM meeting for $\$ 6000$, plus an extra amount for each registrant. Dividing that exorbitant sum by the handful of clinicians was unrealistic. Paying from association coffers was also unacceptable: meetings barely break even and costs would be shifted to students, librarians and independent scholars who have no use for credits, but who have a great deal to teach us. The organizers of that meeting despaired, until they were rescued by a more reasonable provider in another state.

Not obtaining CME accreditation harms both history and medicine. First, meetings no longer attract physicians who cannot afford time for conferences without accreditation. Consequently, clinicians further disengage with historical research, and their loss diminishes the interprofessional experience for others.

Second, failing to accredit humanities research endorses the notion that it is "soft," irrelevant, and unimportant.

Finally, it punishes those rare clinicians who dare to attend anyway. Their investment doesn't "count," leaving them to seek credits that really count elsewhere - at Whistler maybe.

Perhaps the biggest problem for the humanities is a blind spot: health professionals fail to comprehend research disciplines. Instead, the humanities are viewed as static pastimes for personal enrichment, raising sensitivities, and amusement. This is an insult. The humanities can indeed entertain, enrich, and inspire, but they are a form of intellectual enquiry, and as such thrive on research. "Keeping up" is essential for them too.

Here is the irony. Medical history with other humanities - represents precisely those intangibles that medical educators and CME purveyors strive to maintain. So, the endeavour that shares, even embodies, those very goals is being stifled by them.

From a humanities perspective, current CME trends are more about "keeping out" or "keeping down" rather than "keeping up."

\section{Jacalyn Duffin MD PhD}

Hannah Chair of the History of Medicine Queen's University

Kingston, Ont.

All editorial matter in CMAJ represents the opinions of the authors and not necessarily those of the Canadian Medical Association. 